\title{
Multiparametric magnetic resonance imaging findings of prostatic pure leiomyomas
}

\author{
Achados de imagem na ressonância magnética multiparamétrica \\ dos leiomiomas prostáticos puros
}

\author{
Thais Caldara Mussi ${ }^{1}$, Yves Bohrer Costa ${ }^{1}$, Marcos Takeo Obara ${ }^{1}$, Marcos Roberto Gomes de Queiroz ${ }^{1}$, \\ Rodrigo Gobbo Garcia ${ }^{1}$, José Antonio Domingos Cianciarulo Longo ${ }^{1}$, Gustavo Caserta Lemos ${ }^{1}$, Ronaldo Hueb Baroni ${ }^{1}$
}

\begin{abstract}
Objective: To describe the imaging findings of prostatic tumors nonadenocarcinoma on multiparametric magnetic resonance imaging. Methods: A total of 200 patients underwented multiparametric magnetic resonance imaging of the prostate for screening for prostate cancer, from August 2013 to September 2014, followed by biopsy with ultrasound/magnetic resonance imaging fusion. Results: We found three pathologic proved cases of prostatic pure leiomyomas $(0.02 \%)$ in our series and described the multiparametric magnetic resonance imaging features of these prostatic leiomyomas. The imaging findings had similar features to lesions with moderate or high suspicion for significant cancer (Likert 4 or 5) when localized both in the transitional zone or in the peripheral zone of the gland. Conclusion: Pure prostatic leiomyomas had imaging findings on multiparametric magnetic resonance imaging that mimicked usual adenocarcinomas on this test. Radiologists, urologists and pathologists must be aware of this entity and its imaging features.
\end{abstract}

Keywords: Prostate; Leiomyoma; Magnetic resonance imaging

\section{RESUMO}

Objetivo: Descrever os achados de imagem de tumores prostáticos não adenocarcinoma na ressonância magnética multiparamétrica. Métodos: Realizaram ressonância magnética multiparamétrica da próstata para detecção de câncer de próstata 200 pacientes de agosto de 2013 a setembro de 2014, seguida por biópsia com fusão de imagens de ultrassonografia/ressonância magnética. Resultados: Encontramos três casos confirmados histologicamente de leiomiomas prostáticos puros $(0,02 \%)$ em nossa casuística e descrevemos os achados da ressonância magnética multiparamétrica destes casos de leiomiomas. Os achados de imagem foram semelhantes aos de lesões com moderada ou alta suspeição para neoplasia clinicamente significante (Likert 4 ou 5) quando localizados na zona de transição ou zona periférica da próstata. Conclusão: Leiomiomas puros da próstata tiveram achados de imagem na ressonância magnética multiparamétrica que mimetizaram adenocarcinomas. Radiologistas, urologistas e patologistas devem estar cientes destas entidades e seus achados de imagem.

Descritores: Próstata; Leiomioma; Imagem por ressonância magnética

\section{INTRODUCTION}

Pure leiomyoma of the prostate is a rare entity with origin in the Mullerian duct remnant, the prostatic capsule or the periglandular prostatic tissue. ${ }^{(1)}$ Until 1951, the definition of prostatic leiomyoma was confuse, and Kaufman et al. arbitrarily described it as "a circumscribed or encapsulated mass of smooth muscle, measuring $1 \mathrm{~cm}$ or longer in diameter, containing varying amounts of fibrous tissue, but devoid of glandular elements, and which is either obviously prostatic or juxta-prostatic, in origin and position". Their aim was to distinguish it from fibromuscular hyperplasia, bladder neck tumors or clinically insignificant nodules that created discrepancies in the literature. ${ }^{(2)}$ The differential diagnosis between leiomyomas (rare) and stromal nodules (more common) is difficult and sometimes not possible, but differentiation is based on the fact that leiomyomas have well-organized fascicles. ${ }^{(3,4)}$

There are less than 100 cases of pure prostatic leiomyomas described in the literature, and in almost all cases the tumor was large and the patient presented with

\footnotetext{
1 Hospital Israelita Albert Einstein, São Paulo, SP, Brazil.

Corresponding author: Thais Caldara Mussi - Avenida Albert Einstein, 627/701 - Morumbi - Zip code: 05652-900 - São Paulo, SP, Brazil - Phone: (55 11) 2151-4271 - E-mail: thaiscaldara@gmail.com

Received on: Apr 26, 2016 - Accepted on: July 29, 2016

Conflict of interest: none.

DOI: 10.1590/S1679-45082016A03715
} 
urinary and anorectal symptoms, or an altered digital rectal examination. ${ }^{(1,2,5)}$ There are few case reports in the literature describing large prostatic leiomyomas on magnetic resonance imaging (MRI). ${ }^{(1,6,7)}$ However, to our knowledge, there is no article describing the imaging findings of pure prostatic leiomyomas in asymptomatic patients submitted to multiparametric MRI (mpMRI) of the prostate.

\section{OBJECTIVE}

To describe the imaging findings of prostatic leiomyomas on multiparametric magnetic resonance imaging.

\section{METHODS}

\section{Patient population}

From August 2013 to September 2014, a total of 200 patients were submitted to mpMRI before biopsy, in a period up to 6 months. Of those, 189 had an MRI for prostate cancer screening, five for staging and six were in active surveillance. The study was approved by the Research Ethics Committee of the Hospital Israelita Albert Einstein (HIAE), under protocol number 1.446.587, CAAE: 53632916.1.0000.0071.

\section{Magnetic resonance imaging technique and interpretation}

All patients underwent mpMRI of the prostate on a 3 Tesla system (Magnetom Trio, Siemens HealthCare, Erlangen, Germany) using a pelvic phased-array coil. Pre-contrast sequences of the prostate and seminal vesicles included high resolution axial, coronal, and sagittal turbo-spin echo (TSE) T2-weighted images (WI), axial TSE-T1-WI, and axial fat-suppressed singleshot echo-planar diffusion-weighted images (DWI). Diffusion-weighted images were obtained with $b$ values of 50, 400 and 800, with reconstruction of apparent diffusion coefficient maps. In addition, dynamic contrastenhanced imaging of the prostate and seminal vesicles was obtained using an axial $3 \mathrm{D}$ fat-suppressed T1-WI spoiled gradient-echo sequence obtained before and ten times after intravenous administration of $0.1 \mathrm{mmol} / \mathrm{kg}$ of gadopentetate dimeglumine (Magnevist, Bayer Heatlhcare Phamarceuticals, Whippany, NJ, USA), with a 12-second temporal resolution.

All mpMRI cases were graded using a 5-point scale, according to the probability of having a clinically significant prostate cancer, ranging from highly unlikely to highly likely to be present.

\section{Biopsy technique}

As routinely performed in our institution, all patients underwent ultrasound/magnetic resonance imaging fusion for prostate biopsies, with systematic sampling of 12 regions of the peripheral zone, and 2 of the central gland, and additional sampling of the suspicious areas, if present. One of two different ultrasound pieces of equipment was used to fuse the images and perform the biopsies: Aplio 500 with Smart Fusion (Toshiba Medical System Corporation, Minato, Tokyo, Japan) or LOGIC E9 with imaging fusion software (GE Healthcare, Little Chalfont, United Kingdom). We obtained adequate pathological proof of the results through biopsy samples in all these patients.

\section{RESULTS}

From the 200 biopsies, 83 (41.5\%) were negative and $117(58.5 \%)$ positive for neoplasia. Of those 117 positive cases, $113(96.6 \%)$ were acinar adenocarcinomas, $1(0.008 \%)$ was a stromal tumor of uncertain malignant potential and $3(0.02 \%)$ were leiomyomas. The clinical and imaging characteristics of the three leiomyomas are described below, and figures 1 to 3 illustrate the imaging and pathological findings of these cases.

\section{Imaging findings}

The imaging findings of these three leiomyomas had moderate to high suspicion for clinically significant prostate cancer on mpMRI (Likert 4 and 5).

Case number 1 was a 73-year-old man with prostate specific antigen (PSA) of $6.6 \mathrm{ng} / \mathrm{mL}$, palpable nodule on digital rectal examination and negative prior biopsy. mpMRI showed a $12 \mathrm{~mm}$ round nodule in the left midgland of the peripheral zone that abuts the prostate contour, with very low signal on T2-WI, marked restriction diffusion and early enhancement with washout. It was classified as clinically significant disease highly likely to be present (Likert 5) (Figure 1).

Case number 2 was a 60-year man with PSA of $1.7 \mathrm{ng} / \mathrm{mL}$ and alteration in the right apex upon digital rectal examination. mpMRI showed a $8 \mathrm{~mm}$ round nodule in the right apex of peripheral zone, with low signal on T2-WI, moderate restriction diffusion and enhancement. It was classified as clinically significant disease likely to be present (Likert 4) (Figure 2).

Case number 3 was an 81-year-old man with PSA level of $7.0 \mathrm{ng} / \mathrm{mL}$ in active surveillance and normal digital rectal examination. mpMRI showed a $28 \mathrm{~mm}$ poorly-defined lesion, in the periurethral area of the transitional zone, with low signal on T2-WI, restriction diffusion and early enhancement. It was classified as clinically significant disease likely to be present (Likert 4) (Figure 3). 

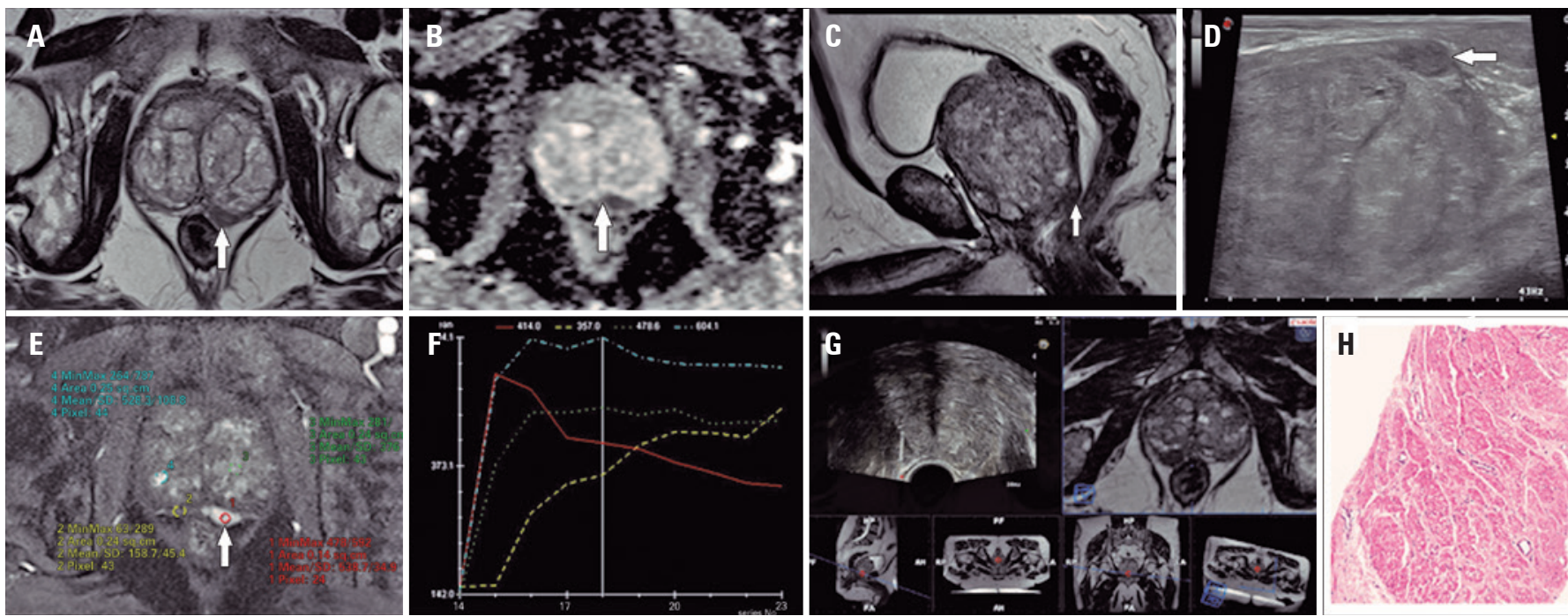

Figure 1. A 73-year-old man with prostate specific antigen level of $6.6 \mathrm{ng} / \mathrm{mL}$, palpable nodule on digital rectal examination and negative prior biopsy. Multiparametric magnetic resonance imaging of the prostate shows a well-defined nodule, with very low signal intensity in the peripheral zone on T2-WI (A and C), intense restricted diffusion demonstrated by a low signal on apparent diffusion coefficient map (B) and hypervascularized pattern, with an early wash-in followed by wash-out curve (E and F). Real time imaging fusion ultrasound/magnetic resonance imaging technique: the nodule seen as a low-signal lesion in the peripheral zone of the prostate on T2-WI (C) appears as a round hypoechoic nodule on ultrasound (D). Systematic biopsy with additional samples of the suspicious area was performed (note that magnetic resonance imaging images were inverted during the procedure) (G), and pathological results demonstrated a pure prostatic leiomyoma (H)
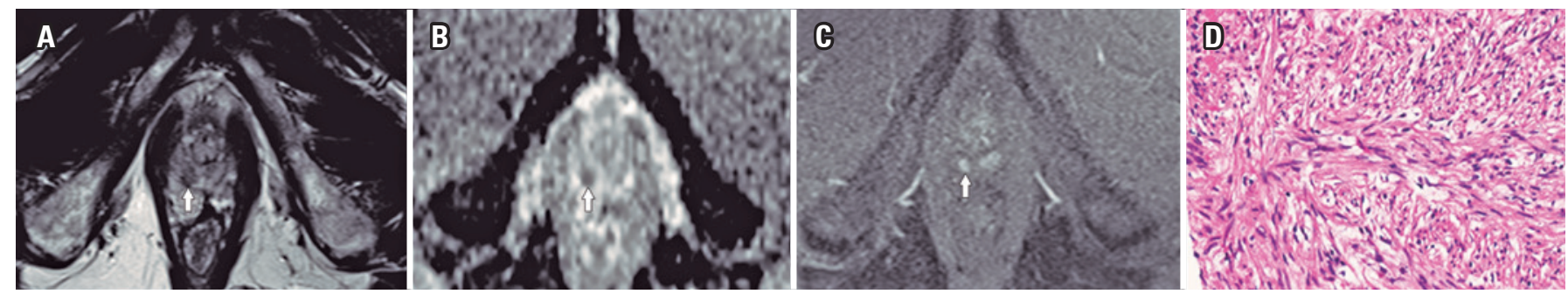

Figure 2. Multiparametric magnetic resonance imaging of the prostate shows a circumscribed nodule in the peripheral zone on T2-WI (A), with moderate restricted diffusion on the apparent diffusion coefficient map (B) and early hypervascularization on the dynamic contrast-enhanced sequence (C). Pathological analysis confirmed a pure prostatic leiomyoma (D)
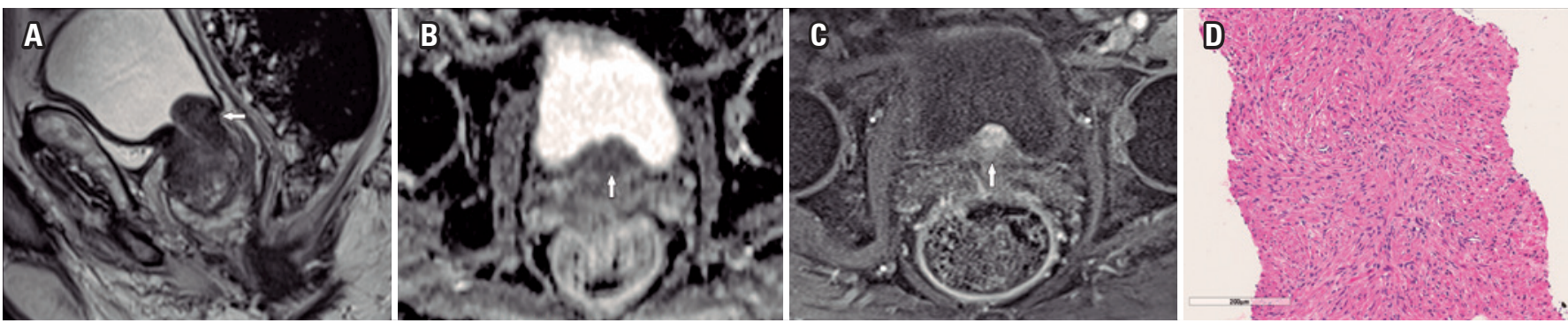

Figure 3. Multiparametric magnetic resonance imaging of the prostate shows a poorly-defined lesion in the periurethral area of the transitional zone $(\mathrm{A})$, with moderate restricted diffusion on the apparent diffusion coefficient map (B), and early hypervascularization on the dynamic contrast-enhanced sequence (C). Pathological analysis confirmed a pure prostatic leiomyoma (D)

All cases were readily detected on ultrasound during the fusion biopsy as well-circumscribed, hypoechoic lesions.

\section{Pathological findings}

Slides showed fragments of biopsy composed of spindle smooth muscle cells, separated by small amounts of collagen. The tumor cells were arranged in an orderly pattern of intersecting fascicles. Individual cells had blunt-ended nuclei with evenly distributed nuclear chromatin. There was no nuclear atypia, tumor necrosis or mitotic activity. Tumor cells had positive immunostaining for desmin and smooth muscle actin. Epithelial elements were not seen within the nodules. 


\section{DISCUSSION}

The use of prostate mpMRI prior to biopsy is well known and established in the literature to increase the accuracy of the procedure. ${ }^{(8-12)}$ The positivity of clinically significant prostate cancer in biopsy is directly related to suspicion grade on mpMRI, and in moderate to highly suspicious cases the positivity of the biopsy ranges from 73 to $100 \%$. $^{(8,13)}$

We described three cases of pure prostatic leiomyoma on biopsies with ultrasound/MRI imaging fusion, all with a likely to highly likely probability of clinically significant prostate cancer on mpMRI using a probability classification.

The etiology of prostatic leiomyoma remains unknown and some authors believe that has embryological anlagen from Mullerian remnants. Other hypotheses are that inflammation and infection transform glandular tissue in smooth muscle and the hypertrophy of this muscle produces myoma, or that infection and arteriosclerosis degenerate the hyperplastic tubular nodules, remaining just smooth muscle stroma and scar tissue..$^{(4,6,14)}$ Most cases are diagnosed as large lesions or in patients presenting with urinary symptoms (obstruction or infection). ${ }^{(6)}$ To our knowledge, there is no study describing the imaging findings of asymptomatic prostatic leiomyomas.

Treatment for prostatic leiomyomas is controversial. Although large lesions are usually surgically removed through radical prostatectomy, smaller tumors, such as in our report, remain a challenge for the urologist (given the possibility of growth, recurrence and malignant transformation, even being rare). Hence, therapeutic decisions should be individualized. ${ }^{(15)}$

\section{CONCLUSION}

Prostatic leiomyomas are lesions that have imaging findings on multiparametric magnetic resonance imaging suspicious for clinically significant prostate cancer. They may present as important mimickers of adenocarcinomas in both peripheral zone and transitional zone of the prostate on multiparametric magnetic resonance imaging. With the increasing use of multiparametric magnetic resonance imaging as a screening tool before prostate biopsy, it is likely that diagnosis of leiomyoma will increase; thus radiologists, urologists and pathologists must be aware of this entity.

\section{REFERENCES}

1. Imai S, Ayabe Y, Liyama T, Muramatsu H, Matsuo Y, Kudo S. Leiomyoma of the prostate: CT and MR findings. Abdom Imaging. 2002;27(6):674-6.

2. Kaufman JJ, Berneike RR. Leiomyoma of the prostate. J Urol. 1951;65(2):297-310.

3. Hansel DE, Herawi M, Montgomery E, Epstein JI. Spindle cell lesions of the adult prostate. Mod Pathol. 2007;20(1):148-58. Review.

4. Mellas S, Bouchikhi AA, Tazi MF, Khallouk A, Elammari JE, El Fassi MJ, et al. Prostatic leiomyoma: a case report. Case Rep Urol. 2012;2012:702762.

5. Vassilakis GB. Pure leiomyoma of prostate. Urology. 1978;11(1):93-4.

6. Barba J, Tolosa E, Panizo AF, Berían JM. Prostatic leiomyoma. Case report. Arch Esp Urol. 2011;64(7):631-5.

7. Kitajima K, Kaji Y, Imanaka K, Hayashi M, Kuwata Y, Sugimura K. MR imaging findings of pure prostatic leiomyoma: a report of two cases. J Comput Assist Tomogr. 2006;30(6):910-2.

8. El-Shater Bosaily A, Arya M, Punwani S, Emberton M, Kirkham A, Freeman A, Ahmed HU. Re: Multiparametric magnetic resonance imaging guided diagnostic biopsy detects significant prostate cancer and could reduce unnecessary biopsies and over detection: a prospective study: JE Thompson, D. Moses, R. Shnier, P. Brenner, W. Delprado, L. Ponsky, M. Pulbrook, M. Böhm, A.-M. Haynes, A. Hayen and P. D. Stricker J Urol. 2014;192:67-74. J Urol. 2015; 193(2):735-6; discussion 736 .

9. Porpiglia F, Russo F, Manfredi M, Mele F, Fiori C, Bollito E, et al. The roles of multiparametric magnetic resonance imaging, PCA3 and prostate health indexdwhich is the best predictor of prostate cancer after a negative biopsy? J Urol. 2014;192(1):60-6

10. Rastinehad AR, Turkbey B, Salami SS, Yaskiv 0, George AK, Fakhoury M, et al. Improving detection of clinically significant prostate cancer: magnetic resonance imaging/transrectal ultrasound fusion guided prostate biopsy. J Urol. 2014;191(6):1749-54.

11. Pokorny MR, de Rooij M, Duncan E, Schröder FH, Parkinson R, Barentsz JO, et al. Prospective study of diagnostic accuracy comparing prostate cancer detection by transrectal ultrasound-guided biopsy versus magnetic resonance (MR) imaging with subsequent MR-guided biopsy in men without previous prostate biopsies. Eur Urol. 2014;66(1):22-9.

12. Johnson LM, Rothwax JT, Turkbey B, Rais-Bahrami S, Wood BJ, Figg WD, et al. Multiparametric magnetic resonance imaging of the prostate aids detect lesion progression. J Comput Assist Tomogr. 2014;38(4):565-7.

13. Wysock JS, Rosenkrantz AB, Huang WC, Stifelman MD, Lepor H, Deng FM, et al. A prospective, blinded comparison of magnetic resonance (MR) imagingultrasound fusion and visual estimation in the performance of MR-targeted prostate biopsy: the PROFUS trial. Eur Urol. 2014;66(2):343-51.

14. Michaels MM, Brown HE, Favino CJ. Leiomyoma of prostate. Urology. 1974;3(5):617-20.

15. Hossain D, Meiers I, Qian J, MacLennan GT, Bostwick DG. Prostatic leiomyoma with atypia: follow-up study of 10 cases. Ann Diagn Pathol. 2008;12(5):328-32. 